\title{
Teknik sinematografi praktis menggunakan smartphone bagi dosen pengabdi di Universitas Negeri Makassar
}

\author{
Baso Indra Wijaya Aziz ${ }^{1}$, Abd. Aziz Ahmad ${ }^{2}$ \\ ${ }^{1,2}$ Fakultas Seni dan Desain, Universitas Negeri Ma kassar
}

\begin{abstract}
Experiences from the fields of science cultivated by lecturers can be poured in to te aching materials, textbooks, reference books, research materials, study materials, and the like that a refull of benefits. The be nef it of this training is to help the devoted lecturers in making compulsory outcomes from community service a ctivities in the form of making videos. Video making material in the form of a collection of photos and videos that a re owned so that it will become a digital archive that can be enjoyed by everyone. For this rea son, cin ema tographic basic techniques are needed a a basic principle so that lecturers can process their photos and videos so they can talk a lot in a ccordance with the desired motivation. The steps are in the form of (1) smartphone settings (2) pict ure taking technique (3) narration making (4) editing technique (5) uploading to YouTube social media. Through the implementation of the Community Partnership Program it can be seen that the interest and enthusiasm of lecturers in Ma kassar State University is very high to learn and maximize the functions and feat ures of smart pho nes, b asic techniques for taking good pictures, how to process and edit video with a smartphone, to feel First ex perience of uploading videos to YouTube social media.
\end{abstract}

Key words: lecturer, documentation, smartphone, cinematography

\section{PENDAHULUAN}

Sejalan dengan perkembangan teknologi digital, maka guru dan dosen serta peserta didik dituntut harus mampu beradaptasi dengan keterampilan abad $21\left(21^{\text {st }}\right.$ Century Skills) yaitu bisa berfikir kritis dan memecahkan masalah, kreatif dan inovatif serta ketrampilan komunikasi dan kolaborasi. Selain itu, keterampilan mencari, mengelola dan menyampaikan informasi serta terampil menggunakan informasi dan teknologi (Wibawa 2018).

Adapun masalah yang dihadapi dosen untuk membuat video sebagai berikut: (1) data berupa foto atau video yang dimiliki sangat banyak dan semuanya bercampur dengan data-data lainnya, (2) gambar berupa foto atau video yang dibuat/ dihasilkan kebanyakan tidak memenuhi kriteria pengambilan seperti terlalu goyang, terlalu gelap, atau terlalu terang, sehingga menyulitkan saat editing, (3) kebanyakan dosen belum mampu memaksimalkan fitur foto dan video smartphone untuk mengambil gambar, (4) minimnya pengetahuan untuk melakukan editing video menggunakan smartphone dan (5) kesibukan aktivitas membuat tidak adanya waktu luang untuk belajar secara khusus cara editing video.

\section{METODE PELAKSANAAN}

Dengan segala kelebihan yang dimiliki smartphone, fitur tambahan yang saat sekarang ini menjadi fitur unggulan berbagai merek smartphone yaitu kemampuan kamera yang mempunyai kualitas tinggi. Kemampuan kamera untuk mengambil foto tak kalah baiknya dibanding kamera profesional, meski tentunya ada perbedaan namun tidak begitu jauh, untuk kebutuhan dokumentasi pribadi dinilai sudah sangat mumpuni. Begitu juga perekaman video menunjukkan beberapa opsi mulai dari kualitas Standart Definition (SD), High Definition (HD), Full High Definition (FHD), hingga Ultra High Definition (Ultra HD/4K) dan masih banyak tingkatan resolusi di atasnya pada seri tinggi smartphone lainnya.

Bisa dikatakan bahwa perangkat yang sangat menunjang aktivitas kegiatan dosen adalah smartphone. Berkesesuaian dengan pelatihan pengabdian yang dilakukan dengan fokus memberikan teknis dasar sinematografi bagi dosen 
pengabdi dengan perangkat smartphone yang dimiliki. Hal ini senada dengan (Putri, Hamdan and Yulianti 2017) bahwa dalam pelaksanaan kegiatan pengabdian kepada masyarakat, media digital digunakan sebagai sumber referensi pengembangan program pengabdian dan penggunaan media digital sebagai bentuk publikasi hasil PKM.

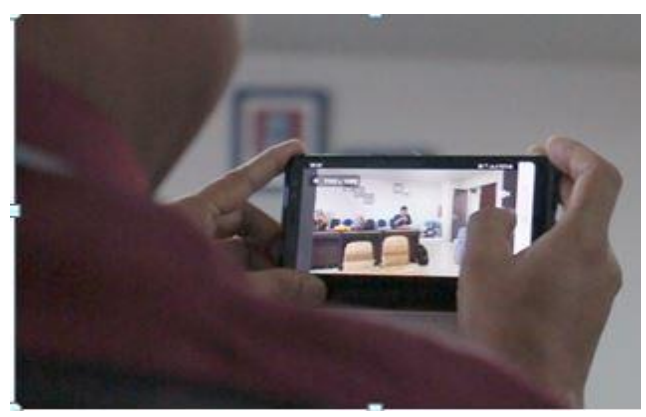

Gambar 1. Pengambilan video menggunakan smartphone

Tujuan dari pelatihan teknik sinematografi praktis ini adalah memberikan kemampuan dasar bagi dosen pengabdi untuk memaksimalkan smartphone yang dimiliki sehingga dapat mengolah foto dan video menjadi tayangan audio visual yang mampu menyampaikan pesan dengan baik.

Metode yang dilakukan meliputi tahapan berikut ini: (1) Persiapan dan pembekalan. Persiapan yang dilakukan berupa merancang video tutorial yang akan dijadikan materi pada pelaksanaan kegiatan. (2) Pelaksanaan kegiatan dilakukan dengan cara memberikan materi tentang wawasan perkembangan kamera digital hingga penggunaan smartphone untuk kepentingan dokumentasi. (3) Rencana keberlanjutan program tidak hanya sekedar pelatihan pada saat itu saja, namun kami membuat kelas online konsultasi teknis maupun non teknis teknik dasar sinematografi bagi para peserta yang telah mengikuti kegiatan pelatihan. Kelas online dibuat dalam bentuk WhatsApp Group (WAG) sehingga dapat dengan mudah berbagi informasi editing video maupun masukan terkait karya-karya video yang telah dibuat.

\section{HASIL DAN PEMBAHASAN}

Hari Kamis tertanggal 11 Juli 2019 telah dilaksanakan Program Kemitraan Masyarakat dengan judul "PKM Teknik Sinematografi Praktis Menggunakan Smartphone Bagi Dosen Pengabdi di Universitas Negeri Makassar”.

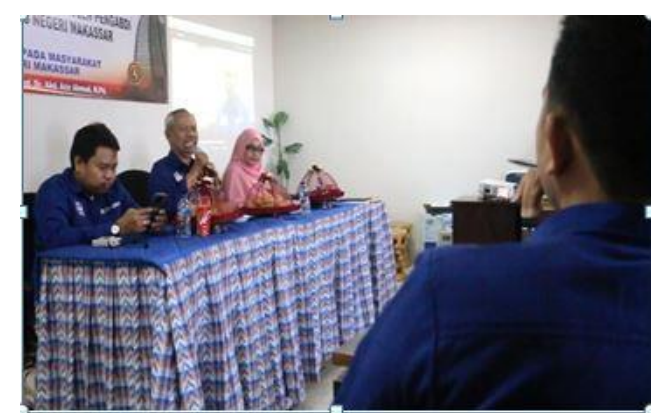

Gambar 2. Pemateri memberikan gambaran wawasan di era digital

Untuk memaksimalkan pelatihan yang diberikan maka kami memberi batasan jumlah peserta yang berasal dari berbagai fakultas yang ada di Universitas Negeri Makassar. Peserta pelatihan yang ikut sebanyak 25 orang yang berasal dari Fakultas Matematika dan Ilmu Pengetahuan Alam, Fakultas Teknik, Fakultas Ekonomi, Fakultas Bahasa dan Sastra, Fakultas Ilmu Sosial, dan Fakultas Seni dan Desain.

Berdasarkan hasil karya dari peserta dosen pengabdi berupa pembuatan video kegiatan pengabdian kepada masyarakat dapat dijabarkan terkait materi Ilmu Pengetahuan dan Teknologi (IPTEK) yang diberikan sebagai berikut.

\section{A. Pengaturan Smartphone}

Berupa kiat-kiat atau cara mengatur kamera sebelum siap digunakan mengambil video. Pengaturan smartphone lainnya yang dilakukan yaitu mengunci exposure (gelap terangnya gambar) sehingga video yang dihasilkan tidak mengalami pencahayaan yang berubah-ubah. 


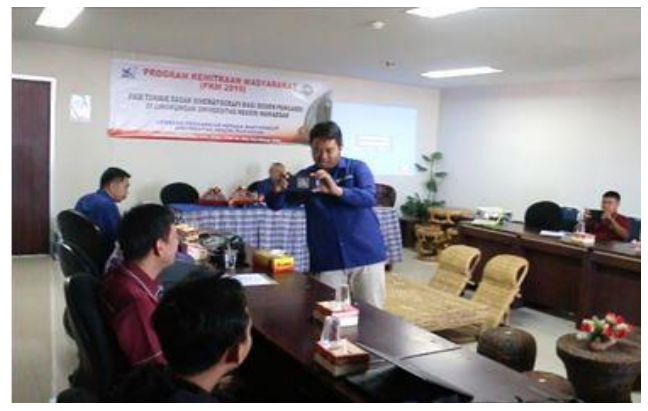

Gambar 3. Pemateri memberikan contoh teknik pengambilan gambar

\section{B. Teknik Pengambilan Gambar}

Mengambil rekaman wawancara dengan durasi waktu yang agak lama diperlukan adanya tripod agar gambar yang dihasilkan menjadi statis tanpa adanya pergerakan yang akan akan mengganggu kenyaman penonton.

\section{Membuat Narasi}

Pada tahapan ini dilakukan setelah materi video sudah ada dan telah siap dikerjakan pada tahap editing.

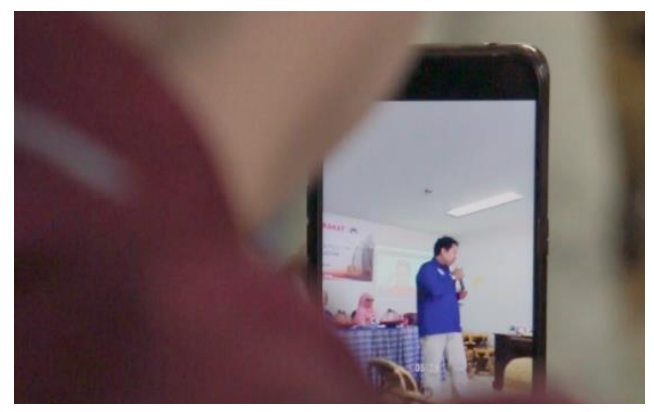

Gambar 4. Kecenderungan dosen mengambil video secara vertikal

Narasi menjadi pemandu yang dapat mengarahkan penonton memahami video yang sedang ditonton.

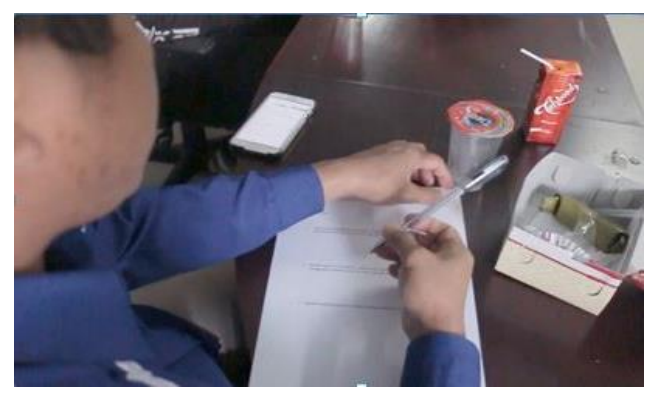

Gambar 5. Peserta pelatihan membuat narasi

\section{Teknik Editing Menggunakan Smartphone}

Pada tahapan ini merupakan tahapan yang paling menentukan sekaligus paling seru untuk menuangkan segala bentuk kreativitas dalam mengolah materi video yang dimiliki. Gambar demi gambar dirangkai menjadi satu kesatuan yang dapat menyampaikan pesan sesuai dengan yang diinginkan. Proses pengambilan gambar telah selesai, kemudian setelahnya produksi film memasuki tahap editing. Dalam tahap ini, shot-shot yang telah diambil, dipilih, diolah, dan dirangkai hingga menjadi satu rangkaian kesatuan yang utuh (Pratista 2017). Pada pengolahan video hasil karya dosen pengabdi menampilkan sekumpulan video dan foto yang disusun disertai dengan animasi text.

\section{E. Upload ke Media Sosial Youtube}

Setelah video rampung diedit, maka langkah selanjutnya agar dapat dinikmati sebagai karya audio visual dengan tujuan memberi manfaat bagi banyak orang yaitu dengan mengunggah ke youtube, salah satu plaform penyedia video dengan pengguna terbesar di dunia. Pembuatan video oleh dosen pengabdi sudah ada sejumlah dosen yang mengunggah ke akun youtube masing-masing dengan tujuan arsip pribadi maupun sebagai laporan pelaksanaan pengabdian masyarakat yang alamat link yang bisa dibagikan kepada orang lain.

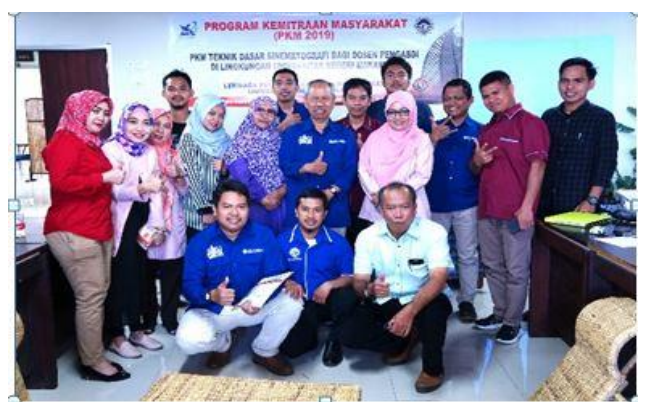

Gambar 6. Pemateri dan peserta pelatihan setelah pelaksanaan kegiatan

\section{KESIMPULAN}

Pelaksanaan pelatihan berupa teknik dasar sinematografi bagi dosen pengabdi di lingkungan Universitas Negeri Makassar, mempunyai target utama yaitu dosen pengabdi dapat merancang dan membuat video yang efektif, efisien, informatif, 
dan komunikatif berdasarkan kegiatan pengabdian masyarakat yang dilaksanakan.

Beberapa poin penting yang telah dicapai dan menjadi indikator keberhasilan pengabdian masyarakat ini yaitu:

1. Dosen pengabdi mampu memaksimalkan fungsi dan fitur video dari kamera smartphone. Pemahaman dasar berupa prinsip kerja video pada smartphone. Pengetahuan ini memungkinkan dosen pengabdi dapat menggunakan segala macam smartphone yang ada.

2. Dosen pengabdi mampu melakukan pengambilan gambar dengan komposisi pengambilan gambar yang baik disertai dengan pergerakan kamera yang simpel namun memberi kesan dinamis. Pengetahuan ini dapat diaplikasikan pada pengambilan foto maupun video.

3. Dosen pengabdi memahami konsep dalam pembuatan video sehingga dapat menyampaikan pesan dengan komunikatif. Pesan yang disampaikan berupa bahasa gambar (visual) yang memuat kronologi pelaksanaan kegiatan. Penggunaan text dan narasi menjadi unsur penting yang mendukung penyampaian pesan yang diinginkan.

4. Dosen pengabdi mampu melakukan kerja editing dengan memanfaatkan perangkat smartphone yang dimiliki sehingga dapat memiliki kesempatan dan mobilitas yang tinggi dalam membuat video dimana saja dan kapan saja.

5. Menarik minat dan ketertarikan bagi dosen pengabdi untuk berkarya video. Setelah pelatihan dibentuk WhatsApp Group (WAG) sebagai bentuk pendampingan lanjutan bagi rekan-rekan dosen pengabdi. Ada beberapa dosen yang membagikan hasil karya videonya. Peluang dosen dalam menciptakan materi pembelajaran maupun menjadi content creator, yaitu pembuat video kreatif menjadi terbuka luas.

\section{UCAPAN TERIMA KASIH}

Terima kasih kepada Ketua Lembaga Penelitian dan Pengabdian Masyarakat (LP2M), Universitas Negeri Makassar, Prof. Dr. Ir. H. Bakhrani Rauf, M.T. dan semua kepala pusat di lingkungan LP2M beserta segenap stafnya. LP2M sebagai pihak yang mendanai Kegiatan PPM PNBP Pusat sekaligus bertindak sebagai mitra. Ucapan terima kasih terkhusus kepada para Dosen Pengabdi perwakilan dari Fakultas Matematika dan Ilmu Pengetahuan Alam, Fakultas Teknik, Fakultas Ilmu Sosial, Fakultas Ekonomi, dan Fakultas Seni dan Desain dalam lingkungan Universitas Negeri Makassar yang telah menjadi peserta pelatihan sehingga kegiatan pengabdian ini dapat berjalan lancar sesuai yang diharapkan.

\section{DAFTAR PUSTAKA}

Pratista, Himawan. 2017. Memahami Film. 2nd Edition. Edited by Agustinus Dwi Nugroho and Yosua Aji Febrianto. Yogyakarta, DIY: Montase Press.

Putri, Dian Widya, Stephani Raihana Hamdan, and Yulianti. 2017. "Perilaku Bermedia Digital dalam Pelaksanaan Tridarma Perguruan Tinggi di Kalangan Dosen Unisba." MediaTor (Universita Islam Bandung) 10: 11-24.

Wibawa, Sutrisna. 2018. Pendidikan dalam Era Revolusi Industri 4.0 